\title{
Shaping of sustainable citizenship among young people of Kulhudhuffushi, Maldives and Hamilton, New Zealand: context, conditions and experiences
}

Shaaliny Jaufari

\begin{abstract}
Background: Engagement of young people is essential for achieving sustainable outcomes both locally and in the global context. Democratic processes appear to be the most facilitative mechanism to hold governments to account with governments becoming more receptive to pro-environmental policies when there is input from citizens to do so. While there is concern about a general lack of participation in traditional forms of political processes, particularly among young people, there are those who are carving a space for themselves as active citizens within a system that is often times contradictory to their lives. In this context, this paper looks at the lived experiences of a small sample of active young people in Kulhudhuffushi island of Maldives and Hamilton, New Zealand to examine the contexts and conditions that lead to and sustain these forms of sustainable citizenship.

Results: In-depth interviews conducted with young people in both locations found similarities within both groups in terms of motivating factors, knowledge and support networks, lifestyle practices, and conceptualisations of citizenship. Early exposure to natural environments, role models and participation in actions and networks helped to create active citizenship, while lack of conducive spaces and cultural attitudes impeded activism.

Conclusion: The results show that providing opportunities for early interactions with nature, and participation in actions and activist networks is vital for fostering and sustaining active citizenship. Additionally local and national groups and institutions need to facilitate spaces conducive for organising and alternative narratives, as well as promoting a counter culture to the current carbon heavy system. The findings contribute to literature on listening to youth voices in environmental and climate activism.
\end{abstract}

\section{Plain English summary}

As the environment movement has grown, a specific type of citizenship practice characterised by environmentally conscious lifestyles and activism has emerged. Research has shown that governments are more receptive to the needs of people when there is pressure from citizens to do so. Young people of today will be inheriting the consequences of the decisions that are being made in the present, and it is important to include their voices in achieving the kind of

\section{Correspondence: shaaliny.jaufar@gmail.com}

Political Science and Public Policy, Faculty of Arts and Social Sciences, Te Kura Kete Aronui, University of Waikato, Hamilton, New Zealand change that are beneficial to the current times as well as in the future. This paper attempts to look at the lives and experiences of young people who are part of activism and green lifestyles in order to examine the factors and experiences that promote and sustain such active young citizens. The study focuses on Kulhudhuffushi island of Maldives and Hamilton, New Zealand, and identifies common factors and differences in motivations, sources of information, support networks, lifestyle practices, and also barriers to their activism. The findings showed that, while different they existed in different contexts, there were common factors such as time spent in nature from a young age and

(c) The Author(s). 2020 Open Access This article is licensed under a Creative Commons Attribution 4.0 International License, which permits use, sharing, adaptation, distribution and reproduction in any medium or format, as long as you give

appropriate credit to the original author(s) and the source, provide a link to the Creative Commons licence, and indicate if changes were made. The images or other third party material in this article are included in the article's Creative Commons licence, unless indicated otherwise in a credit line to the material. If material is not included in the article's Creative Commons licence and your intended use is not permitted by statutory regulation or exceeds the permitted use, you will need to obtain permission directly from the copyright holder. To view a copy of this licence, visit http://creativecommons.org/licenses/by/4.0/. 
role models that motivated young people to become active citizens. It also showed that limited spaces for mobilising, cultural attitudes and systems that discourage activism are barriers for active young citizens. Opportunities for learning and organising as well as mentoring is important to create the conditions for active citizenship among young people and such support systems needs be facilitated and made more accessible.

\section{Introduction}

The United Nations 2030 Agenda for Sustainable Development [1] emphasises a crucial role for young women and men, hailing them as critical agents of change. Engaging young people in decision making on sustainable development is key to achieving sustainable outcomes both locally and in the global context, particularly as they are the ones who face the consequences of current actions or inaction on the threats caused by climate change and environmental degradation [2]. The concept of sustainable development emphasises the integration of issues such as environmental conservation, equity and well-being into development interventions, which have traditionally been associated with economic development and modernisation [3, 4]. The goal of sustainable development becomes even more urgent in the face of the threat of climate change, especially in the context of neo-liberal capitalism.

There are considerable challenges in leading lifestyles that promote and embody sustainability within a system that is environmentally exploitative. Yet, it is noteworthy that there are groups of young people who are managing to carve a space for themselves as "sustainable citizens" $[5,6]$. It is important to look at the experiences and actions of such young people to understand the factors and conditions that lead to and sustain behaviour conducive to sustainable lives.

This paper looks at the specific lived experiences and factors that shape young citizens committed to a sustainable future in the face of climate change. It undertakes a comprehensive analysis of literature and in depth interviews conducted with a small sample of active and engaged young people who are part of environmental groups, environmentally leaning political organisations or active in environmental causes, in two cross-national locations - Kulhudhuffushi island in the Maldives and Hamilton, New Zealand. The aim of this research was to examine the conditions and experiences that motivate young people and to determine the kind of cultural and structural support required to foster and sustain the kind of citizenry necessary for the current context. The study also aims to contribute to literature on youth voices in environmental and climate activism.

\section{Theorisations of green citizenship}

Citizenship denotes participation in civic or political activities. The purpose of this participation differs in the two major perspectives on citizenship that has prevailed over the years. While liberal citizenship emphasises maximising individual liberty $[7,8]$, republican citizenship in contrast places emphasis on responsibility and civic virtue $[9,10]$. However, it is increasingly observed that there are manifestations of different kinds of citizenships concurrently existing within communities that are complex and diverse [5]. This is also true within the paradigm of green citizenship.

The initial focus of the practice of environmental citizenship was on individual action such as responsible consumption and waste minimisation. Recent theorisations have however called for a more holistic interpretation $[8,10,11]$. For instance, Dobson [12] differentiates between environmental citizenship, which is a more individualistic manifestation of green citizenship, from ecological citizenship. He defines ecological citizenship as an ecological form of post-cosmopolitan citizenship that deals in the currency of non-contractual responsibility, and one that inhabits the private as well as the public sphere, and one that is explicitly non-territorial (p. 259). The impact of wider socio-economic structures and power differentials is also acknowledged in such theorisations [10] as well as the inequalities and injustices from globalisation [13] and a "range of different geographical spaces and ecological contexts located at a range of distances from the state" [11] (p. 514). This increases the scope and spheres in which green notions of citizenship occurs.

Theorisations of sustainable citizenship go beyond individual actions and propose a challenge to the existing socio-economic and political systems. This perspective includes more actors, arenas and complex clusters of relationships. Kurian et al. [5] propose moving beyond dichotomies such as rights and responsibilities, public and private, etc., in their conceptualisation of sustainable citizenship. For example they argue that the focus on either rights or responsibilities in classical theorisations of citizenship is too simplistic and that both rights and responsibilities are important in the context of sustainability. They also mirror feminist critiques of the importance of the private sphere, arguing that decisions made in the private sphere around areas such as consumption, transport and energy conservation have impacts on the planet.

Micheletti and Stole [6] state that sustainable citizenship has the potential to challenge and change the underlying structural causes that have caused global environmental destruction and social injustice while Kurian et al. [5] calls for a commitment to deliberative democratic politics that allow a clash of ideas leading to 
the emergence of a deliberated set of shared values ( $\mathrm{p}$. 437). This requires moving beyond traditional sites and norms of citizenship and participating in actions both in the private and public sphere that promotes sustainability and social justice. An active citizenry is also essential to push towards the kind of transformative change that advocates for such principles.

\section{Changing nature of youth citizenship}

Currently there is a concern in the industrialised world with what is being perceived as a "crisis in modern democracy" with decreasing proportions of people voting, declining memberships of political organisations, and decreasing trust and confidence in politicians and political systems [14] (p. 3-4). This decrease in civic culture is thought to be most present among youth, with young people being less interested and knowledgeable about political issues, less trusting of traditional forms of public authority and less likely to engage in civic participation than adults [15].

Nonetheless, any lack of participation should not be simply explained as apathy of citizens but should be understood within the specific context in which it occurs. As Dahlgren [16] states, "Democracy is being transformed as its social, cultural, and political foundations evolve, and the character of participation is a part of these large developments" (p. 29-30). There is evidence to suggest that broader issues such as the voting system, political, economic and environmental context of the country, as well as socio-demographic factors such as age, gender, ethnicity and socio-economic status are predictors of how citizenship is understood and practiced by young people $[15,17]$.

Furthermore, rather than place the blame on youth as choosing to be inactive members within the democratic processes, some commentators state that it is actually political elites who have excluded them and failed to keep pace with the social and cultural changes within societies $[14,18]$. For instance, youth voices remain underrepresented in literature on climate change [19-21]. While mechanisms for youth consultations such as youth forums, focus groups, and web portals are being introduced into governance processes to facilitate collaborative governance arrangements, existing approaches of doing things still tend to remain [22], potentially undermining the objectives under which they were established. In addition, innovations with regards to communication with citizens are regarded as "add-ons" rather than "must-haves" that is dependent on budgeting and leadership of the institutions [23]. Mechanisms that are used sometimes pay lip service rather than enable full participation and co-production of policy [24]. There is also little recognition of young people as important stakeholders in generating recommendations on climate change mitigation [25].
Research has demonstrated that when young people are given the opportunity to participate, they do engage in community based issues and campaigns [26, 27] and that young people require structures and mechanisms that are appropriate for them [28]. The deterrent in most cases is not the motivation to participate, but rather the accessibility or applicability of the mechanisms used for participation. Hence, although the number of young citizens engaging in traditional and hierarchical forms of political and civic participation might be declining, that does not mean that their interest in politics is, and it is more likely that they are involved in more nontraditional processes such as grassroots social movements and protest behaviour $[29,30]$. The most recent movement around climate action, lead by young people, is a good example.

Dalton [30] argues that changes in patterns of participation in contemporary politics are due to changing norms of citizenship. Bennett [31] describes a highly personalised and individualistic form of citizenship that seem of the liberal tradition, while at the same time being communitarian with participation in non-governmental activities, volunteering and social movements that promote the greater good. New forms of civic engagement have also emerged, particularly through the proliferation of online media and internet-based movements [31-33]. In his research into trends in social capital in Sweden, Bo Rothstein [34] also found increasing individualism among young Swedes, with decreasing participation in traditional hierarchical and organised forms of social activity. But he contends that it was not egoistical individualism but rather solidaristic individualism. In addition, recent years have seen the act of resistance being contradictorily viewed as a form of participation, particularly in the environmental and anti-globalisation movements in that some scholars view conflict, struggle and resistance as conducive to greener outcomes and sustainability [10, 35]. Hence, a multitude of factors such as the socio-economic and political context, peers, technological developments, and even every day interactions [36] play important roles in shaping and sustaining the kind of citizenship that young people demonstrates.

\section{Research context}

Two locations from two seemingly different countries, Maldives and New Zealand, that nevertheless face similar risks and challenges with regards to climate change was the focus of this research. Both countries are island states, and dependent on industries that are highly sensitive to environmental resources and changes in climate. In addition, both countries are relatively small in terms of population, and while being relatively small gross emitters of greenhouse gases, their futures depend to an extent on the actions of larger countries. They, however, 
are dealing with these threats within very different socio-political and economic contexts: Maldives as an emerging democracy with nascent democratic processes, a volatile political climate and a developing economy, while New Zealand is an established democracy with changing norms of political participation and activism, and a wealthy economy. In this regard, a multiple-case study approach was chosen to use the same logic as multiple experiments whereby findings from multiple cases are assessed to see whether they support any broader pattern or conclusion [37].

Nevertheless, both countries have a role to play domestically and internationally not only to maintain their reputation as 'green' countries but to demonstrate the much needed leadership on climate change. For this reason there needs to be a citizenry that is aware and active in advocating for strong action and putting pressure on their respective governments to implement such policies.

\section{Kulhudhuffushi, Maldives}

The importance of citizen activism for sustainable development is particularly relevant to a vulnerable nation like the Maldives, a small island nation in the Indian Ocean. The island of Kulhudhuffushi is the capital island of Haa Dhaalu atoll in the North of Maldives, with a population of 8440 [38]. The island is famous for boat building and producing coir rope, and is also a trading hub for the agricultural produce in the region due to a produce market that is held every Saturday. In terms of facilities and infrastructure, it is one of the more urban islands in the North of the country, with a regional hospital, a harbour and secondary educational institutions.

The interviews for the research took place during a period of upcoming Presidential elections in a tumultuous political context. The country embarked on democratic reforms from the early 2000 s that resulted in the first ever multi-party democratic elections in 2008. The subsequent years increased the space for expression and political activism. However, the country faced major challenges in adjusting to the newly established democratic processes leading up to an unexpected transfer of power in 2012 and subsequent political polarisation and turmoil. The spaces for democratic participation and expression was shrunk with a decrease in trust in public institutions and concerns over high levels of corruption [39]. In addition, there was growing concern among environmentalists and development practitioners about large scale projects started by the then incumbent government that involved destruction of reefs and natural ecosystems. This was particularly relevant for Kulhudhuffushi.

The island of Kulhuduffushi gets its name from a mangrove in the island. In the lead up to the Presidential elections of 2018 the Government made the decision to destroy a part of the mangrove to build a domestic airport in the island [40]. There was opposition to the project by environmentalists inside and outside the island, leading to a national protest movement against the destruction of the mangrove. However, the project went ahead despite the protests and the airport was opened in September 2018 close to the election date [41]. As it happened, the ruling party lost the election.

A group of young people led the activism against the mangrove destruction within Kulhudhuffushi and interviews were conducted with some of these youth while the airport was being built but before the Presidential elections.

\section{Hamilton, New Zealand}

New Zealand has been mirroring the kind of changes in political participation that has been seen globally, with political party membership declining and political activism shifting from political parties towards more organised pressure or issue based groups [42]. The 2017 general election, however, saw the dislodging of the conservative National-led government that had been in government since 2008 and the election of a coalition government with centre left parties that ran on a platform of social democratic and environmentalist policies.

Hamilton is the fourth most populous city in New Zealand located in the central North Island. It has an estimated population of 160,000 within the Hamilton City Council area and around the half of its residents are under 30 years [43]. Environmental risk factors facing the wider Waikato region including threats to biodiversity and high carbon emissions are also issues facing Hamilton. Even though the last Parliamentary elections in 2017 demonstrated a decrease in popularity of the strongly neo-liberal National government, the two electorates of Hamilton voted in two National MPs to Parliament.

While Hamilton is not considered a hub for political and environmental activism compared to the larger cities such as Wellington and Auckland, there is a community of young people who are trying to live sustainable lives and who advocate for environmental action. At the same time, schoolchildren from Hamilton began to participate in the School Strikes for Climate movement that began in 2019, which was a positive change in terms of building a culture of participation and activism. The present research, however, only focused on participants over the age of 18 in order to get a more broad based and longer term view of experiences and support systems that facilitated their active citizenship.

Unlike participants from Kulhudhuffushi, participants from Hamilton did not come from one group of young people who had all been part of one local movement. They were from different groups, as well as participants who were individuals that were passionate about issues related to environmentalism and climate change. 


\section{Methods}

Semi- structured interviews were conducted with young people aged between 18 and 30 years. Participants were recruited through contacting environmental and political organisations, university clubs, and subsequently from snowball sampling.

Interviews in Kulhudhuffushi were conducted in mid 2018 in the lead up to the Presidential elections that year. As a result of facing pressure and threats due to their activism against the destruction of the island's mangrove some of the young people within the activist group from the island were reluctant to talk to an outsider. Hence, fewer interviews were conducted in Kulhudhuffushi than planned. Fieldwork in Hamilton was conducted in early to mid 2019. Table 1 shows the demographic information of the participants.

\section{Framework of analysis}

Dahlgren [32] writes about "civic cultures" (p. 103) that operate at the everyday level of citizens and play an important part in how people develop into citizens, which are derived from social relations and institutions. He views them as cultural resources that citizens can draw from to exercise citizenship. Dahlgren also presents a framework for analysing civic cultures, namely the dimensions of knowledge, values, trust, spaces, practices and identities, that interact together to produce the civic culture in a given community. Conducive elements such as these allow citizens a civic identity, helping them participate in democratic processes to further their cause of sustainability.

In the same vein, Horton [44] conducted ethnographic research into the everyday lives of green activists in Lancaster, England to explore environmental citizenship. He found that green activists demonstrate environmental

Table 1 Participants' demographic summary

\begin{tabular}{lll}
\hline & Kulhudhuffushi & Hamilton \\
\hline Age & 6 & 5 \\
$18-24$ & 2 & 5 \\
$25-30$ & 8 & \\
Race/Ethinicity & \\
Maldivian & & 2 \\
Māoria & & 6 \\
Pākeha & & 1 \\
S. Asian & & 1 \\
African & & \\
Occupation & & 6 \\
Student & 5 & 4 \\
Employed (full time) & 3 & \\
\hline
\end{tabular}

Indigenous New Zealander

${ }^{\mathrm{b}} \mathrm{New}$ Zealander of European descent citizenship voluntarily, and that activism is not learnt through formal teaching but "steadily embodied through participation in green networks, spaces, material assemblages, and times" (p. 144). Horton concludes that environmental citizenship found in Lancaster emerges through practice rather than pedagogy, and the culture from which the specific behaviours emerge needs to be promoted.

There are overlaps and interconnections between the dimensions of the two frameworks. For the purposes of the present research, I draw from these two frameworks and formulated the interview questions around the elements of knowledge, networks, spaces, practices and identity. I used these elements as codes during data analysis to generate the common and different factors and themes that arose from the conversations with the participants. From these themes, I examined the practice of sustainable citizenship of young people in Kulhudhufushi, Maldives and Hamilton, New Zealand, through their a) motivations, b) sources of knowledge, c) networks, d) spaces, e) practices, and then the resulting $\mathrm{f}$ ) identity.

The following sections will contain the findings from the two locations, illustrated with quotes from the interviews. The participants are referred to with an alphanumeric code that identifies their location, gender and a random numeric number. For instance $\mathrm{Kf} 3$ is a participant from Kulhudhuffushi who is female.

\section{Fostering sustainable citizenship Motivations}

The most significant factor that cultivated a love for the environment was early exposure to natural environments. This was a common factor among participants across both locations.

Many participants reported to have spent a lot of their childhood outside in the natural environment. Participants from Kulhudhuffushi reported that growing up most of their time after school or with friends was spent in natural spaces. They also reported an inexplicable affinity to nature at a young age that made them upset when they see nature harmed in anyway or rubbish thrown around. As Kf8 stated "I will get emotional at people cutting down trees".

Additionally, the proximity to natural spaces and the ocean while living in the island enabled them to experience changes first hand. As a result, participants reported concern at observing the changes in the island such as erosion of beach areas and disappearing of green spaces as a motivation for fighting to protect the natural environment of the island. Some participants expressed sadness and frustration about natural spaces that they closely associate with their childhood disappearing and being replaced by housing or other physical buildings.

Similarly, all of the Hamilton participants spoke about spending a lot of time in natural environments at a 
young age that made them develop an affinity for nature. In fact, the single most significant motivating factor for the participants of Hamilton that made them develop a love and concern for the environment was early exposure to nature.

Role models were a strong motivating factor for most of the participants as well. Kulhudhuffushi participants were particularly motivated by a national climate change activist who was originally from the island and who was also a mentor for a lot of the participants interviewed. They were also inspired by the activism of environmental and sustainable development activists and organisations from the capital, Male'.

For a lot of Hamilton participants, knowing about or meeting young people who were trailblazers in politics or in areas of sustainability prompted them to follow in their paths. This included young activists such as New Zealand's Green Party MP Chloe Swarbrick and activists and bloggers outside of New Zealand. As Hf7 stated "I came across a blogger who could fit all of her waste from like 2-3 years in a small jar. And it was just quite confronting and made me realise that I had not been thinking about how my waste impacted the natural environment that I love so much. It woke me up to the fact that I could be doing a lot more than I was".

Peers were a significant motivator for the Kulhudhuffushi interviewees. The majority of the participants started their environmental activism in school. After leaving school one of the participants started an environmental NGO and a lot the participants, who were also a part of her circle of friends, joined the NGO. As Km2 said, "I joined the NGO to support my friend, once I joined I realised this is something that cannot be left undone".

Another influence mentioned less frequently by Kulhudhuffushi participants was family members, specifically grandparents. Kf1 stated "I spent most time in my childhood with my grandmother, and she loved the environment". This could be due to the culture of living with extended families in the island, where grandparents looked after children while the parents worked or were occupied in other domestic activities. However, family members were not found to be a significant motivating factor for becoming environmentally or politically conscious for Hamilton participants. In fact, while some participants credited their exposure to nature at an early age to their parents and family, a lot of the participants reported that their family members were quite different to them in views about politics and the environment.

\section{Knowledge}

Internet sources were the most accessed source of information for the young activists of both Kulhudhuffushi and Hamilton. Majority of them used social media and obtained information from people and organisations they followed. As Kf8 stated, "I follow active people on social media and read from the links they post".

For Hamilton participants who were members of NGOs or political parties their respective organisations were important sources of knowledge. These members attended meetings of the organisations, followed other members on social media and participated in Facebook and other chat groups hosted by their organisations. Participants from both of the locations obtained information particularly relevant to their respective countries from activists and environmentalists from the capital.

Participants who were university students, accessed academic journals to get more information on their areas of interest. Academic articles was reported by most of the participants who were students from both of the locations as the most trusted source of information.

Accessing information from personal blogs were common among the participants who were advocates of sustainable lifestyles. As Hf7 stated "I did read a lot of people's personal blogs which potentially may not be as scientific but had kind of a human element to it because it was about how people can change behaviour and how people have gone on the same journey". Hf9 reported that "There's aren't a lot of NZ blogs on such topics because the movement has kind of started".

One significant source for information relevant to political activism for Kulhudhuffushi participants were the youth programmes on leadership and participation that was conducted by NGOs in Male' during the years Maldives was undergoing democratic reforms after its first multi-party Presidential elections in 2008. This used to be an annual programme open to the participants from the whole country, but at the time of this research the annual programme had been discontinued. There were however some ad hoc programmes for youth that was still being held either in Male' or at regional locations by Male' based NGOs and UN organisations, which many of the participants of the research had participated. The participants reported that these programmes had helped them immensely and supported them to go ahead and carry out projects that they developed with the technical assistance they received. In addition, the participants reported that it enabled them to find out how government processes work and how to advocate for issues accordingly.

Additionally, Kulhudhuffushi participants reported that they gained a lot of knowledge during their activism against the destruction of the mangrove. After the issue grew into a national movement there were a lot of environmentalists and technical people, as well as political activists, who visited the island in support, and many of the participants were involved in showing them around the mangrove and the island. The participants reported that they learnt a lot about the special characteristics of 
mangroves, its relationship to climate change and disaster mitigation, as well as political activism in the process of being part of the movement.

Nevertheless, accessing sources of knowledge was one area where the Kulhudhuffushi participants found challenging. Some participants were enrolled in undergraduate programmes and had access to academic and specialist sources of information. However, most of the participants, particularly those residing full time on the island, relied on activists and groups in Male', and technical people who visit for ad hoc workshops held in the island for information that were relevant to their location.

\section{Networks}

The group of environmental activists in Kulhudhuffushi had a close-knit network among themselves. Those who left the island for education or employment also kept in contact with those who remained in the island.

However, for most of those who remained in the island there was limited connections and support networks with the wider national organisations and almost no connections with international organisations. $\mathrm{Km} 4$ reported that he worked alone in advocating for the causes he was concerned about, that included talking to people and posting messages on social media. Kf3 did report making connections with other activists she met when she participated in workshops in other islands. Those from the island residing in Male', however, were part of wider national networks in environmental and political activism. Participants who were doing their undergraduate studies in the capital had access to more academic and technical networks and established environmental groups in the capital. Some had participated in international conferences on climate change.

In contrast to the participants of Kulhudhuffushi who were all part of a group of individuals who had mobilised for a cause together, the participants from Hamilton were from different environmental and political organisations and also individuals who had no connection to a particular group. As a result they were not part of the same network and participants had varying levels of connection with other people and networks within and outside Hamilton.

The participants who were part of organisations had more networks than those who were not. Participants who were members of an NGO, for instance, had opportunities to be part of the wider network of that NGO nationally, participate at events outside of Hamilton, and through these events, make connections with people who were active and leaders in their fields.

On the other hand, participants who were not part of any groups did not have as many connections with people and organisations in their area, especially outside of Hamilton. Active groups and individuals within Hamilton were also quite limited and a lot of the communication and networking happened for events and actions that were national in scope. Nevertheless, there was still a group of people in Hamilton that coordinated and organised advocacy events.

There's definitely like a little bit of network in Hamilton. Different kinds of similar groups who work together like allied groups on things (Hf1)

However, some participants observed that since the group of people participating in those events was so small, there would normally be the same people who always attended such events.

When it came to social networks most of the Kulhudhuffushi participants reported that their close circle of friends were like-minded people as well. For some of the participants their friendship circle changed as a result of ideological differences.

My social circle is environmentally conscious. I have lost friends because I have to argue about these things. They can be politically on different sides but we agree on environmental issues $(\mathrm{Km} 2)$

However the social networks of Hamilton participants varied in terms of ideology with most of the participants reporting that people in their friend circles were not active politically, had different political views and did not necessarily lead sustainable lifestyles. Hm4 reported that "I still have friends I get along with quite well but we don't agree on certain things. But we're adults and there's one belief that I have like $99.5 \%$ of people if they ask them what they really, really care about its exactly the same things as I do. They just have different ideas of how to get there".

Nevertheless, some participants from both locations did report that some people in their social networks were influenced by their lifestyle to change their behaviour. For instance Hf7 reported "My close social circle is not necessarily into the same environmental stuff but I had noticed that over the years I've seen them make small changes. That's super encouraging for me because it means that I've done a good job in making the whole zero waste movement relatable and achievable".

\section{Spaces}

Horton [44] highlights the importance of spaces for communication and participation for the expression of alternative ideologies. However, in the case of Kulhudhuffushi there was an absence of such spaces. Participants reported that a lot of the meetings and idea generating happened in living rooms of people's houses. There were spaces in some educational institutions that the participants could access for organising events but 
this was due to personal contacts within these two institutions and not from an established institutional policy granting access to use their spaces for such purposes.

There were no spaces such as a particular café in the island, as found in Horton's study, that was a known place to hang out for young people with similar ideologies. In fact, most participants reported that they did not frequent cafés or restaurants at all due to financial constraints. However, many of the participants spoke of meeting in open natural spaces like the beach for organising events as well as for social gatherings within the group.

During the time the interviews took place the country overall was facing severe government-imposed restrictions to freedom of expression and spaces for assembly. While the participants were not aligned with any political party, their protest against the destruction of the mangrove was perceived as being critical of the then government's airport project. As a result, the participants reported harassment by the supporters of the government in public, as well as threats on social media. As a result some of the participants had stopped being publicly involved in activism, and had stopped social media activism as well under the advice of their family members. However, shortly after the interviews took place the government was voted out at the Presidential elections of 2017, and was replaced by a government that was perceived to be more democratic in terms of allowing the space for expression and activism.

As with Kulhudhuffushi participants, Hamilton participants did not identify any specific spaces in Hamilton that were frequented by or considered as a hangout for people with similar ideologies and lifestyles. Go Eco, the environment centre in Hamilton, was mentioned by most of the participants, as an organisation that either collaborated with them or hosted an event organised by them. However, there were some participants who had not had any interactions with the centre and also those who did not consider that many events and spaces in Hamilton were particularly attractive to young people.

I love what Go Eco do, but I often don't feel inspired to be involved in their stuff. I don't know whether that's just a generational thing or ... " (Hf1)

It was interesting to note that while a lot of the Hamilton participants were university students, they did not find their university to be a site that promoted activism or facilitated organising by young people. Even participants who were part of organisations reported that the spaces where they end up doing a lot of the organising were the homes of members. Hm4 states that "We find there are spaces but there's almost always a cost involved".
Some participants talked about informal gatherings organised by specific groups they were a part of where they got the opportunity to interact with like-minded people and be a safe space to express their views.

We do things like green drinks. So we go to a pub or a bar or a café or whatever once a month and you can just talk about things you have in common, meet new people or talk about issues that you want more information on and learn what other people's perspectives are. I guess the thing is like its people coming together and creating the space rather than like a building where you go (Hf3)

A substantial amount of interaction, organising and communicating happened on virtual spaces to overcome the lack of physical spaces. This included Facebook groups, Facebook messenger, Twitter, chat applications, and the Slack app for specific campaigns. Chat groups were also the medium though which more senior members of organisations that participants were a part of and those that reside in Male' in the case of Kulhudhuffushi or other cities in the case of Hamilton guided and mentored the participants in carrying out activities or provided information and advice.

\section{Practices}

Participants of both the locations demonstrated a spectrum of practices involving active and engaged citizenship within both their private lives and in the public sphere.

They lead environmentally conscious lifestyles such as becoming vegetarian or vegan, choosing to walk over the use of motorised vehicles, avoiding single use plastic, purchasing less and being responsible consumers. Some participants facilitated sustainable practices for others as well. As Kf3 reported "I bring metal straws in bulk from eBay and distribute to those who want to commit to not using plastic straws".

In addition to leading sustainable lifestyles, participants were active in campaigns and participated in activities in their political and environmental organisations. Those who were not part of a formal group, and even some participants who were, engaged in political and advocacy activities in their individual capacities as well, particularly the participants from Hamilton. This included a wide ramge of activities such as writing blogs on sustainable living, volunteering, doing research or running for Mayor and City Council.

Some of the participants from Kulhudhuffushi were also continuously engaged in monitoring the effects from the mangrove destruction, and communicating them on various social media platforms. This information was used by national activists to lobby and hold 
relevant government agencies to account. Participants also participated in broader national environmental and other areas of activism, or volunteered for social causes. Some participants reported feeling compelled to act responsibly due to their reputation as environmental activists. As Kf8 stated "I have to be more careful, I have to show by example".

However, participants in both of the locations reported that they faced challenges in engaging in sustainable lifestyles and advocating for environmental protection. They report the sense of always going against the grain. As Kmf states "I refuse plastic bags from shops. They used to look strangely at me but now they know I don't take it". Hamilton participants talked about challenges they faced in getting other people involved and active in Hamilton, one of the main issues being the attitudes and beliefs of other people.

Public will is one thing. Public not being on board, and there's still climate change deniers! (Hf2)

People don't really care or think there's nothing we can do. There's lots of people who think that (Hf1)

This was mirrored by Kulhudhuffushi participants as well, as Km2 stated "I feel very troubled by the fact that people are not concerned about these issues. They will say I don't care. What they don't realise is that at some point, what they say they don't care about will eventually affect them".

Participants also talked about the practical difficulties of living more sustainably in a system that is based on increasing consumption. Hf3 stated that "One thing I've noticed is how hard it is to live differently in our society because everything is mass produced and just simplified for the majority and if you want to live any differently it's so hard". Some of the participants at times found going against the grain in terms of their practices quite challenging.

I'm afraid that some of the appeal I have (in my job) is that I am quite "normal". I would like to make further changes but I would also like to be employed and progress in society" ( $\mathrm{Hm} 4)$

\section{It can sometimes feel a little bit lonely (Hf7)}

Some of the participants referred to the conservative nature of Hamilton when compared to other areas in terms of both political affiliation and culture as not being very conducive for political and environmental action. But one participant stated that perhaps the more political minded individuals move out to places like Wellington which is considered to be more politically active, and hence the perception people have of places becomes a self-fulfilling prophecy.

\section{Identity}

When participants talked about their conception of what it meant to them to be citizens two main common themes arose from the descriptions.

The first theme was a sense of responsibility. All of the participants across the two locations reported feeling a sense of responsibility for being mindful of other people's rights as well as protecting the rights of the environment. For most of the participants, the responsibility to contribute to the society was as important as the rights that comes with citizenship. For Māori participants from Hamilton their sense of responsibility comes within a Māori worldview. As Hm4 states "It's the same kind of belief we have in my iwi, ${ }^{1}$ the idea that we're only here for a small period of time and we need to ensure that over that period of time we are not damaging it so much that people who come after us can't use it anymore".

The second common theme that came through was being engaged politically and to have their voice in policy and decision making. For instance, Kf3 emphasised that "You can really call yourself a citizen if your voice is heard in the place you live. You have to talk about policies, your rights. Just voting is not enough".

The major difference between participants from both locations was the connection to place. Kulhudhuffushi participants had a strong connection to place and when they talked about the concept of citizenship there was an emphasis on responsibility towards the place they were from.

In contrast, the theme of connection to the local community or place did not come through from Hamilton participants. This may be because a significant number of participants were from other areas of Waikato region or outside who had moved to Hamilton for education or employment. Most participants had a more generalised perception of at the level in which their responsibility lies. As Hm4 stated: "Waikato is not my iwi, but when they talk about long term sustainability projects or long term goals for people here or New Zealand as a whole it still connects with me".

\section{Discussion}

This research explored the conditions and factors that enabled young people to be engaged citizens committed to a sustainable future. It focused on two outwardly different communities in two countries and examined the experiences of active young individuals. It is interesting

\footnotetext{
${ }^{1}$ Māori tribe or extended kinship group associated with a distinct territory
} 
to highlight from the findings that while there were context and location specific factors identified that caused the young people to lead active and sustainable lifestyles, there seem to be commonalities to their experiences as well.

Early exposure to natural environments seems to be a common factor among both the groups, and instrumental in fostering a love for the natural environment. This is facilitated by either living in close proximity to nature or having family members who spent time outside in natural environments. Family members did not need to imbibe sustainable principles but provide opportunities for their children to be exposed to as much nature as possible. Facilitating an emotional connection to nature and living being through such exposure appears to be a crucial starting point towards environmental activism.

Role models and access to networks that were politically and environmentally active was an important factor in motivating young people to be sustainable citizens, as well as their primary sources of information and support in their activism. However, social networks were not found to be a significant factor in sustaining their sustainable practices and activism in both locations as most of the participants had people of varying ideologies within their social circles. Participants were a source of behaviour change of the people in their social circles than vice versa.

There was a lack of spaces in both locations for the articulation of alternative ideologies and interactions between like-minded groups. This is a reflection of the fact that the cultures surrounding sustainable citizenship did not represent the majority in their respective locations, and while the young people manage to carve out a space for themselves, they still operate within their personal spaces or collective private spaces. For instance in Hamilton people held their own green gatherings and created temporary spaces themselves.

Nevertheless, it is important to emphasise that while an early exposure helped young people develop a sense of responsibility towards nature, it was their actual participation in various aspects of activism that led to sustainable citizenship. For participants in Kulhudhuffushi, this involved participation in youth leadership programmes that was tailored in a way to mentor participants in executing a campaign or project for a cause, or joining the environmental NGO, which some of the participants did initially to support their friends. These opportunities eventually led them to be strong activists in the campaign against the destruction of the mangroves. For the participants in Hamilton it was getting an opportunity to participate in a campaign, or joining a political party or an NGO and becoming a part of the wider network within it. While a love of nature lead to an environmentally conscious lifestyle, being a part of a group or a cause and being connected to its broader networks enabled political and environmental activism.

Participants in both locations were joined together in the sense of responsibility they felt towards the protection of the natural environment. This was the main theme in their articulations of their civic identity. The affinity to the environment developed at a younger age and then the knowledge and experience gained from their influencers and networks brought about a sense of responsibility, which formed the basis of their practice of citizenship. Participants of Kulhudhuffushi also had a strong sense of connection to place in their responsibility to protect natural resources. For Māori participants, the connection to place went beyond their immediate community and was influenced by the concept of guardianship within the Māori worldview. This is significant as this is a key theme among indigenous activists across the world who are at the forefront of environmental and climate activism.

The experiences and practices of the participants of this study mirror the theorisations of sustainable citizenship in that they move beyond the individual and are grounded in the notion of responsibility towards communities and nature $[8,10]$, and is practiced within both the public and private spheres [5]. They are also cognisant of and influenced by the wider socio-economic and political structures [10, 17] and everyday interactions with their surroundings, networks and peers [36]. The focus of their citizenship for most, except for some Kulhudhuffushi participants, was also not territorial [11] and existed at various levels.

The young people in this research demonstrated the broadened scope of youth citizenship beyond traditional forms of citizenship. As Bennett [31] suggests it is highly individualised in parts where participants practice sustainable and ethical lifestyles in their personal lives and also conducts individualised activism over the internet and social media while at the same time espousing communitarian principles of social justice and responsibility towards other people and natural environments. The proliferation of social media and internet has facilitated activism while dispersed over a large geographical area but having national and even global connection. This was helpful to sustain activism and maintain networks within a context like Hamilton where there was no prominent culture of activism. It also facilitated the activism of Kulhudhuffushi participants when space for expression and political activism was shrinking.

This speaks to the challenges facing active citizenship in both mature and fledgling democracies. While Kulhudhuffushi participants faced shrinking freedoms for expression during their activism, Hamilton participants were impeded by a culture within their location that did not encourage or support sustainable citizenship. So 
while personal experiences, access to networks, and participation in activism itself, help to motivate and foster active citizenship, the wider socio-cultural and political factors are also critical in creating the conditions in which it can be sustained in the longer term.

As mentioned previously, the fieldwork in the Maldives was conducted during a politically volatile period with decreasing space for civic activism. The subsequent change in government to one that is perceived to be more democratic would have implications on the experiences and practices of the Maldivian participants that needs to be followed up for further analysis. While the small sample of the study was a limitation in terms of representativeness, effort was made to make the sample as diverse as possible, particularly within the context of Hamilton. Additionally, the Hamilton chapter of the School Strike for Climate movement that began functioning from 2019, and whose members were not part of the study, is an interesting development that requires to be explored for further insights into sustainable citizenship within the Hamilton context.

\section{Conclusion}

In both Kulhudhuffushi and Hamilton, civic cultures [32] were found that impeded active citizenry in general. However, young people still managed to carve out a way to either raise their voices for a more sustainable future or live in a manner that safeguarded the environment. This was made possible through their experiences within nature and knowledge gained through interactions with role models and peers, demonstrating that opportunities and activities to engage young people in causes and actions are more effective means to cultivate and support sustainable citizens than pedagogy [44].

This poses interesting questions in a rapidly urbanising world on how we can ensure that children grow up with access to nature and green spaces to foster an affinity for nature from a young age. In addition, civic education programmes need to be tailored in a way that is actionbased and guides and mentors young people to design and implement activities for causes that concern them. Support networks need to be strengthened for young people in non-urban centres to allow them to access knowledge and skills that is not available to them locally. And finally, local and national groups and institutions should play a significant role in providing spaces conducive for organising and expressing alternative ideologies as well as promoting counter cultures to the dominant carbon heavy system to bring the fringe to the mainstream.

\section{Acknowledgements}

The author acknowledges the feedback of Professor Priya Kurian, Professor Debashish Munshi, Dr. Patrick Barrett and Dr. Raven Cretney from the University of Waikato, who reviewed earlier drafts of the manuscript.

\section{Author's contributions}

The author of the article was responsible for designing and carrying out the fieldwork, analysis of data and writing the manuscript. The author(s) read and approved the final manuscript.

\section{Funding}

The author was awarded the Dr. Zena Daysh Fellowship on Sustainable Development towards their PhD research. Funds from the fellowship were used for research expenses such as travel and accommodation. The funding body had no role in the design, data collection, analysis or writing of the research.

\section{Availability of data and materials}

The data for the research includes interview transcripts. They are not publicly available as participants talk about their personal lives and experiences and hence they contain in some cases very specific personal information that could be identifiable or attributed to the respective participant. Requests for data can be considered on a case by case basis.

\section{Ethics approval and consent to participate}

Approval for the research was obtained from the Human Research Ethics Committee of the Faculty of Arts and Social Sciences, University of Waikato, for the fieldwork of this research. Consent was obtained in writing from all participants prior to the interviews.

\section{Consent for publication}

Participants were given an information sheet prior to the interview that included a description of the research and that the findings will be the basis of a PhD thesis, as well academic articles, book chapters or conference presentations. The participants were also informed that they would not be referred to by name but with an alphanumeric code. The consent for publication was sought in the consent form that participants signed before the interviews.

\section{Competing interests}

The author declare that they have no competing interests.

Received: 17 September 2019 Accepted: 26 November 2020

Published online: 07 January 2021

\section{References}

1. United Nations. Transforming our world: the 2030 agenda for sustainable development: author; 2015. Available from: https://sustainabledevelopment. un.org/content/documents/21252030\%20Agenda\%20for\%20Sustainable\%2 0Development\%20web.pdf.

2. Hayward B. Children, citizenship and environment: nurturing a democratic imagination in a changing world. London: Routledge; 2012.

3. Redclift M. Sustainable development (1987 - 2005): an oxymoron comes of age. Sustain Dev. 2005;13:212-27.

4. World Commission on Environment and Development. Our common future Oxford: Oxford University Press; 1987.

5. Kurian PA, Munshi D, Bartlett R. Sustainable citizenship for a technological world: negotiating deliberative dialectics. Citizsh Stud. 2014;18(3-4):435-51.

6. Micheletti M, Stole D. Sustainable citizenship and the new politics of consumption. Ann Am Acad Pol Soc Sci. 2012;644:88-120.

7. Schuck PH. Liberal citizenship. In: Isin EF, Turner BS, editors. Handbook of citizenship studies. London: Sage Publications; 2002.

8. Dobson A. Environmental citizenship: towards sustainable development. Sustain Dev. 2007;15:276-85.

9. Dagger R. Republican citizenship. In: Isin EF, Turner BS, editors. Handbook of citizenship studies. London: Sage Publications; 2002.

10. Barry J. Resistance is fertile: from environmental to sustainability citizenship. In: Dobson A, Bell D, editors. Environmental citizenship. Cambridge: Massachusetts Institute of Technology; 2006. p. 21-48.

11. Bullen A, Whitehead M. Negotiating the networks of space, time and substance: a geographical perspective on the sustainable citizen. Citizsh Stud. 2005;9(5):499-516.

12. Dobson A. Ecological citizenship. In: Reynolds M, Blackmore C, Smith MJ, editors. Environmental responsibility reader. London: Zed Books; 2009. p. 256-70. 
13. Dobson A. Citizenship and the environment. Oxford: Oxford University Press; 2003.

14. Banaji S, Buckingham D. Defining the issues the civic web young people, the internet and civic participation. The John D. and Catherine T. MacArthur Foundation series on digital media and learning. Cambridge: MIT Press; 2013. p. 1-14.

15. Jugert $P$, Eckstein $K$, Noack $P$, Kuhn A, Benbow A. Offline and online civic engagement among adolescents and young adults from three ethnic groups. J Youth Adolesc. 2013;42:123-35.

16. Dahlgren P. Reinventing participation: civic agency and the web environment. Geopolitics Hist Int Relat. 2012;4(2):27-45.

17. Hayward B, Selboe E, Plew E. Citizenship for a changing global climate: learning from New Zealand and Norway. Citiz Soc Econ Educ. 2015; 14(1):19-27.

18. Farthing R. The politics of youthful antipolitics: representing the 'issue' of youth participation in politics. J Youth Stud. 2010;13(2):181-95.

19. MacDonald JP, Harper SL, Willox AC, Edge VL, Rigolet Inuit Community Government. A necessary voice: Climate change and lived experiences of youth in Rigolet, Nunatsiavut, Canada. Global Environmental Change. 2013; 23:360-71. https://doi.org/10.1016/j.gloenvcha.2012.07.010.

20. Corner A, Roberts O, Chiari S, Voller S, Mayrhuber ES, Mandl S, Monson K. How do young people engage with climate change? The role of knowledge, values, message framing, and trusted communicators. Wiley Interdisciplinary Reviews. Climate Change. 2015;6:523-34. https://doi.org/10. 1002/wcc.353.

21. Haynes K, Tanner TM. Empowering young people and strengthening resilience: youth-centred participatory video as a tool for climate change adaptation and disaster risk reduction. Children's Geographies. 2015;13(3): 357-71. https://doi.org/10.1080/14733285.2013.848599.

22. Eversole R. Community agency and community engagement: re-theorising participation in governance. J Public Policy. 2011;31(1):51-71.

23. Sirianni C. Investing in democracy: engaging citizens in collaborative governance. Washington, DC: Brookings Institution Press; 2009. Available from: https://ebookcentral-proquest-com.ezproxy.waikato.ac.nz/lib/waikato/ detail.action?docID=3004462.

24. Timmerman G. Youth policy and participation. An analysis of pedagogical ideals in municipal youth policy in the Netherlands. Child Youth Serv Rev. 2009;31(5):572-6.

25. MacDonald JP, Harper SL, Willox AC, Edge VL, Rigolet Inuit Community Government. A necessary voice: climate change and lived experiences of youth in Rigolet, Nunatsiavut, Canada. Glob Environ Chang. 2013;23:360-71.

26. Akiva T, Cortina KS, Smith C. Involving youth in programme decision making: how common and what might it do for youth? J Youth Adolesc. 2014:43:1844-60.

27. Hart D, Atkins R, Markey P, Youniss J. Youth bulges in communities. The effects of age structure on adolescent civic knowledge and civic participation. Psychol Sci. 2004;15(9):591-7.

28. Matthews H. Citizenship, youth councils and young people's participation. J Youth Stud. 2001;4(3):299-318.

29. Cross W, Young L. Factors influencing the decision of the young politically engaged to join a political party. An investigation of the Canadian case. Party Polit. 2008;14(3):345-69.

30. Dalton RJ. Citizenship norms and expansion of political participation. Pol Stud. 2008;56(1):76-98.

31. Bennett WL. Changing citizenship in the digital age. In: Civic life online [internet]. Cambridge: MIT Press; 2008. p. 1-24. Available from: https:// mitpress.mit.edu/books/civic-life-online.

32. Dahlgren P. Media and political engagement. Citizens, communication and democracy. Cambridge: Cambridge University Press; 2009

33. Dahlgren P. Young citizens and political participation. Online media and civic cultures. Taiwan J Democracy. 2011;7(2):11-25.

34. Rothstein B. Social capital in the social democratic state. In: Democracies in flux the evolution of social capital in contemporary society [internet]. Oxford: Oxford University Press; 2002. p. 245-88. Available from: https:// ebookcentral-proquest-com.ezproxy.waikato.ac.nz/lib/waikato/detail. action? docID=3051849.

35. Agyeman J, Evans B. Justice, governance and sustainability: some perspectives on environmental citizenship from North America and Europe. In: Smith MJ, Reynolds M, Blackmore C, editors. The environmental responsibility reader. London: Zed Books; 2009. p. 281-91.
36. Wood BE. Researching the everyday: young people's experiences and expressions of citizenship. Int J Qual Stud Educ. 2014;27(2):214-32.

37. Yin RK. Applications of case study research. Thousand Oaks: Sage Publications; 2012

38. National Bureau of Statistics. Maldives population \& housing census 2014. Statistical release 1: population and households. Male', Maldives; 2015.

39. Transparency International. Global corruption barometer 2013: report. Berlin: Transparency International; 2013.

40. Controversal airport project inaugurated. Maldives Indepdendent. 2017.

41. Test flight land at Kulhudhuffushi Airport. PSM News. 2018.

42. McRobie A. Introduction: the study of New Zealand politics. In: Hayward J, editor. New Zealand government and politics. 6th ed. Melbourne: Oxford University Press; 2015.

43. Hamilton City Council. Learning about Hamilton n.d. [Avai006Cable from: http://www.hamilton.govt.nz/our-city/about-hamilton/learning\%20about\%2 Ohamilton/Pages/default.aspx.

44. Horton D. Demonstrating environmental citizenship? A study of everyday life among green activists. In: Dobson A, Bell D, editors. Environmental citizenship. Cambridge: Massachusetts Institute of Technology; 2006. p. 127-50.

\section{Publisher's Note}

Springer Nature remains neutral with regard to jurisdictional claims in published maps and institutional affiliations.

\section{Ready to submit your research? Choose BMC and benefit from:}

- fast, convenient online submission

- thorough peer review by experienced researchers in your field

- rapid publication on acceptance

- support for research data, including large and complex data types

- gold Open Access which fosters wider collaboration and increased citations

- maximum visibility for your research: over $100 \mathrm{M}$ website views per year

At BMC, research is always in progress.

Learn more biomedcentral.com/submissions 